\title{
Social competence of social workers and its relation to the outcome of professional practice in the field of care for special groups
}

Suzan Adel Mohammed Ahmed Rashed (PhD) Assistant Professor at Social Casework department Higher Institute of Social work at Banha

\section{Yaser Snoubar (PhD)}

Assistant Professor, Social Sciences Department (Social Work Program) College of Arts and Sciences Qatar University, Doha, Qatar 

Social competence of social workers and its relation to the outcome of professional practice in the field of care for special groups

\section{Suzan Adel Mohammed Ahmed Rashed (PhD)}

Assistant Professor at Social Casework department Higher Institute of Social work at Banha

\section{Yaser Snoubar (PhD)}

Assistant Professor, Social Sciences Department (Social Work Program) College of Arts and Sciences Qatar University, Doha, Qatar

\section{Abstract:}

This study aims to determine the level of social competence among social workers and its relation to the outcome of professional practice. In light of this, the researchers adopted a social survey methodology. The social competence scale for social workers and the professional outcome scale applied to the study sample of 146 social workers who are working in the field of care for special groups in Cairo Governorate. The results of the study showed that the level of social competence of social workers in the care of special groups is medium with arithmetic mean equal to 3.51. As for the level of professional outcome for social work practice among social workers (sample study), it is medium the arithmetic mean of (2.28). It means, whenever the social competence in the sample of research from social workers increases, the professional outcome of the social work practice in the care of special groups increases. As well as whenever the social competence of social workers decreased, the professional outcome of the social work practice decreased. Thus, the findings are consistent with the research hypotheses. The study found that social competence among social workers has a role in raising the outcome of professional practice in the care of special groups. This study is one of the rare studies that link the variable dimensions of social competence among social workers and the outcome of professional practice.

Keywords: social competence, the outcome of professional practice, social workers, special groups.

\section{Introduction:}

The development of social competence has great importance to the practitioner as it is a preventive factor in mental health. Social competence is an essential factor in the development of social support and has a positive impact on working effectively with others. Professional practice and working with multiple groups require high 
levels of social competence. Individuals with social competence are more capable of achieving professional success. Conversely, those who have problems in social competence face personal problems in their welfare and mental health issues as well as professionally in the face of difficulties in establishing lasting and supportive relationships (Amdurer et al., 2014). Thus, social efficiency has a significant impact on professional practice outcomes.

Social competence can be defined as the ability to successfully participate in social interactions and the ability to form and maintain relationships with other people and meet their needs and desires in different contexts (Stichter et al. 2012). Social competence is an essential skill in daily social interaction. It is essential to improve the adequate performance of prac0titioners in the workplace, 0 but research into measuring these skills is rare (Riggio, 2010). Recent research has shown that successful professional performance and the ability to pursue professional life effectively requires specialists to have a range of behavioral abilities and social and emotional competencies, not just knowledge about motivations, skills, and networks within the organization in which they work. Social competence is the practitioner's ability to recognize, understand, and manage emotional information about other people. Conflict management, teamwork, leadership, and negotiation (Gerli et al., 2015), as well as objectivity, oral communication, communication, group management, development of others, and persuasion, are examples (Boyatzis et al., 2009).

The development of social competence, along with emotional and cognitive, leads to forming a coherent framework in the development of talent and performance in work. Human capital management and access to outstanding professional performance require continuous assessment and development of social competence (Emmerling et al., 2012). Therefore, raising the level of outcome in professional practice requires raising many competencies, the most important of which is social competence.

This is indicated by some studies, including the study of Ahmed Samir Abdel Dayem (2018), where the study aimed to determine the level of dimensions of the competence of the professional performance of social workers and Azhar institutes. The study results revealed the importance of accomplishing of social worker job, in addition to the focus of the social worker on the technical work at the Azhar institutes. 
Saad Zaghloul Saad Study (2018) aimed to determine the level of professional performance of the team in providing integrated care for psychopaths. The technical and material resources of the team, including understanding each discipline of the role of the other specialization, the existence of suitable places for teamwork, holding courses to develop the skills of the team were among the most relevant results of the study. The study came up with a proposed perception from the perspective of the general practice of social work to increase the competence of the team in providing integrated care services for psychiatric patients.

Ibtisam Yahya Bedair's study (2008) aimed to cooperate with other professional efforts, especially teachers, in making the school a field of technical expertise through which they find students to face their present and future lives. The study reached a set of planning indicators to increase the effectiveness of the professional performance of the school social worker from the results of previous studies and the current field study.

Marwa Ahmed Abdel Fattah's study (2011) aimed to evaluate the training programs offered to social workers working in the medical field to improve their professional competence. The results of the study proved that the training program contributed to the development of professional knowledge, skills, and experiences of social workers.

Hind Mohamed Ahmed Sayed's study (2015) aimed to test the impact of the task-focused model in the social workers' acquisition of social skills in dealing with a child with autism. The study found the effectiveness of the task-focused model in providing social workers with social skills in dealing with a child with autism.

Dalia Mohammed Shafi Dahi's study (2015) aimed to test the relationship between the use of a training program of general practice and the achievement of the quality of the professional practice of a youth welfare specialist. The results of the study showed that the training program proved effective in achieving a remarkable degree of quality of professional practice.

Akmal Shahid Hosny Study (2015) aimed at identifying the relationship between graduate programs in improving the professional performance of social workers working at Fayoum University. The results of the study found that social workers working at Fayoum University between graduate and non-graduate students are consistent in (professional knowledge - professional skills - social values). 
The study conducted by Najla Saeed Hassan Al-Qahtani (2013) aimed at reducing the behavior of aggression among secondary school students in the Kingdom of Saudi Arabia. One of the most relevant results of the study was to verify the effectiveness of the model used in this study to develop social competence and modify their attitudes from being demolition elements and sabotage to themselves or the community to individuals with high social competence.

The study conducted by Hussein Mahmoud Salah (2019) aimed to identify the role of the general practitioner works in youth centers on developing young people's life skills. As well as identify strategies, skills, and tools used in the development of life skills, and to identify obstacles that facing the general practitioner in developing young people's life skills. The most important results of the study are the development of a proposed concept from the perspective of the general practice of social work in the development of life skills for young people to assess the roles of the general practitioner.

Khaled Awad Saber's study (2019) aimed at reaching the professional performance requirements of the general practitioner in social work to achieve the sensory integration of autistic children. The results of the study showed the high rates of compatibility by social workers on the requirements of the professional performance of the general practitioner in the social service to achieve the sensory integration of autistic children in all the requirements of the study.

Nemat Hussain Mahmoud's study (2018) aimed to test the effectiveness of a training program to develop the skills of social workers working with hearing-impaired groups. The results of the quantitative and qualitative study showed that the use of a training program contributes to the development of the skills and competence of social workers who work with groups with hearing disabilities, which positively affects the outcome of professional practice.

The study of Samia Arabi Mohammed (2017) aimed at determining the quality of professional performance of social workers in student activities in accredited and non-accredited colleges. The study concluded that the skill and cognitive performance of the social worker came in favor of the accredited colleges.

Mustafa Jamal Abdul Hafeez's study (2017) aimed to identify the requirements of activating the professional performance of the social worker with multiple disabilities and then come up with indicators to develop a training program from an individual service 
perspective. The results of the study proved that the requirements of activating the professional performance were the highest percentage, which are the cognitive requirements, followed by the requirements of the value social worker, then the skills and training requirements, followed by administrative and institutional.

The study conducted by Hind Juma Karni (2016) aimed to determine the quality requirements of the professional practice of social workers in working with individual cases in juvenile care institutions. The results of the study determined the quality requirements of the practice, which represented in the quality of assessment, intervention, evaluation, and termination with the individual case in juvenile care institutions.

Sayed Abdel Hamid's study (2018) sought to test the effectiveness of a training program from the perspective of the general practice of social work to develop professional skills among social workers working with children with Down syndrome with autism spectrum disorders. The results of the study reached the effectiveness of the training program prepared in this study in developing the professional skills of social workers working with this special group.

The study conducted by Rukaya Abdel Moneim El Sayed (2018) aimed at clarifying the outcome of the professional practice of the individual social worker with behavioral cases, identify the requirements that contribute to activate the professional role of the individual social worker with behavioral cases in the school field. One of the most important findings of the study is that there are deficiencies in the knowledge, skills, and professional preparation of social workers.

Samar Tarek Hussein Othman's study (2019) sought to test the effectiveness of evidence-based practice to reduce the problems faced by social workers working with school activity groups. The results of the study showed an improvement in the performance of social workers on the problems they face with school activity groups. This improvement is an outcome of the professional intervention program used by the study.

The study conducted by Alaa Hamed El-Sayed Hamed (2012) aimed to determine the social and economic outcome for the rehabilitation of the mentally disabled, the most significant obstacles, and suggest proposals to increase and strengthen the level of services and rehabilitation care provided by NGOs in the city of Zagazig for the mentally disabled. The study found that the level of economic 
outcome programs for the rehabilitation of mentally handicapped in NGOs as determined by parents is weak as determined by officials is an intermediate level.

In a study conducted by Ahmed Khalifa Ahmed (2004) to determine the social outcome from the practice of individual social work with street children. The results study showed that the practice of individual social workers achieved the desired return by a weighted $72 \%$ in addition to the success of the institution in achieving its objectives. This achieving assisted by the availability of factors such as management follow-up, team collaboration, and availability.

Through previous literature review, researches and studies have focused on the study of social competence as well as the outcome of professional practice with many groups. At the same time, it noted the scarcity of studies dealing with social competence among social workers who are working in the care of special groups.

\section{Study Problem:}

The problem of the study represented in the absence of interest in the social competence of social workers in literature as one of the variables affecting the outcome of professional practice, specifically in the field of care for special groups. This outcome only improved by conducting many studies and research on the relationship between social competence and the outcome of professional practice and identifying factors that help to develop social competence and prevent things that affect it negatively.

\section{Study Objectives:}

1. Identify the level of social competence among social workers (study sample) and its relation to the outcome of professional practice.

2. Identify differences in the degree of social competence among social workers according to age, gender, academic qualification variable, and experience.

3. Provide suggestions to increase the outcome of the professional practice of social workers (study sample).

Study Hypotheses: The current research attempts to test the following hypotheses:

First Hypothesis: There is a statistically significant correlation with a positive relationship between the social competence of social workers and the outcome of professional practice in the care of special groups. 
Second Hypothesis: There is a relationship statistically significant between some demographic variables (gender, age, marital status, academic qualifications, and years of experience) and the degree of social competence.

Third Hypothesis: There is a statistically significant relationship between some demographic variables (gender, age, marital status, academic qualifications, and years of experience) and the outcome of professional practice.

\section{Study Concepts:}

The concept of social competence: Schneider et al. (1996) define social competence as "socially effective behavior and its cognitive, affective, and conative antecedents. Socially effective behavior is behavior that is instrumental in helping people achieve personal and social goals" (p. 471). Craham (1986) defined Social competence as "the ability to interact successfully and effectively with others, in a manner that facilitates harmony with the environment, and helps to achieve personal and professional goals, through the formation of positive relationships that have a continuous nature, enabling the individual to influence others" (Muslim, 2006).

It measured procedurally by a high degree on the dimensions of the Social Competence Scale tool for social workers who are subject to the current study.

\section{Methodology:}

This study belongs to the descriptive and analytical studies, as the problem of the study is predominantly determinative, and it aims at estimating the current situation social competence of social workers and its relationship to the outcome of professional practice in the care of special groups. In this research, researchers adopted the social survey method. This method fits the current study in terms of its subject or the adequacy of the data, which can be collected to describe the relationship between social competence of social workers and its relationship to the outcome of professional practice in the care of special groups.

\section{Sample of the study:}

A sample of the Social workers who are working in special needs service centers in Cairo Governorate was select. The total number is (235). According to Stephen Thompson's formula, the sample size determined by (146) singles randomly assigned them (68) males, (78) females. 


\section{Tools of the study:}

The researchers relied on two measures to collect data and study and analysis of the subject of the study:

(A) Social competence of social workers (prepared by Dr. Suzan Adel Rashed, 2019)

(B) A measure of the professional return on social work practice (prepared by Dr. Mohamed Abdel Hakim Khalaf, 2019). The building of the tools used in the study clarifies as the following:

A- The Social Efficiency Scale of Social Workers: The researcher relied on the Social Competence Scale (prepared by Dr. Suzan Adel Rashed, 2019). The scale designed in two parts, as follows:

Part 1: Includes personal data (gender, marital status, age, academic qualification, and years of experience).

Part 2: Includes (32) items to measure social competence distributed over four dimensions: (first dimension: confidence and self-assertion, the second dimension: communication and social compatibility, the third dimension: dealing with social problems, the fourth dimension: social control and flexibility).

\section{Correction:}

To answer the paragraphs of the scale, the researchers, when designing the scale, adopted the five-dimensional Likert scale to determine the degree of each term, as shown in the following table:

Table (1) shows the weights of the paragraphs

\begin{tabular}{|c|c|c|c|c|c|}
\hline Response & Strongly Agree & Agree & Neutral & Disagree & Strongly disagree \\
\hline Weight & $\mathbf{5}$ & $\mathbf{4}$ & $\mathbf{3}$ & $\mathbf{2}$ & $\mathbf{1}$ \\
\hline
\end{tabular}

The total score of the scale present in the sum of its partial scores, and for partial measures in the sum of its item scores, whenever the total score higher, this was an indicator of social competence. The maximum score obtained on the scale as a whole is (160), and the minimum score (32).

\section{Honesty and consistency of the Social Competence scale in current} research:

A - Honesty: The researcher relied on two types of honesty:

1. The validity of the arbitrators (the virtual): It includes the ratios of the agreement of the arbitrators on the paragraphs of the scale; Where the Social Competence Scale of social workers was present to several professors of social work, psychology, and field practice to be judged in light of:

2. The extent to which the phrase linked to each axis of the study.

3. In terms of phrase formulation. 


\section{In terms of content.}

Accordingly, the general dimensions of the scale modified. Some phrases modified, and phrases less than $85 \%$ of the agreement deleted - the ratio of the agreement calculated according to the Geithman equation.

Internal consistency reliability (factor): The researcher calculated the internal consistency of the scale paragraphs on a sample size of (21) single:

Table (2) : Internal consistency between variables of social competence scale among social workers and the total degree

\begin{tabular}{|c|l|c|c|}
\hline M & \multicolumn{1}{|c|}{ Scale dimensions } & $\begin{array}{c}\text { Correlation coefficient } \\
\text { with a total score }\end{array}$ & $\begin{array}{c}\text { Level of } \\
\text { significance }\end{array}$ \\
\hline 1 & $\begin{array}{l}\text { The first dimension: confidence and } \\
\text { self-assertion }\end{array}$ & 0.787 & 0.000 \\
\hline 2 & $\begin{array}{l}\text { The second dimension: } \\
\text { communication and social harmony }\end{array}$ & 0.861 & 0.000 \\
\hline 3 & $\begin{array}{l}\text { Third dimension: dealing with } \\
\text { societal problems }\end{array}$ & 0.821 & 0.000 \\
\hline 4 & $\begin{array}{l}\text { The fourth dimension: control and } \\
\text { social flexibility }\end{array}$ & 0.978 & 0.000 \\
\hline
\end{tabular}

Illustrated by the table above, the dimensions of social competence scale of social workers have a statistically significant at the level of (0.05), this gives an indication of the high coefficients of internal consistency, as well as its reference to the high sincerity and enough of indicators to be trusted in the application of the current study.

B- Reliability: The researcher used two methods to ensure the reliability of the scale:

1. Alpha Cronbach: The researchers applied the scale to a sample and determined the psychometric characteristics, and then re-applied on the same sample after (15) days, i.e., two weeks between the first application and the second. The researchers then calculated the reliability of the social competence scale of the social workers by using the reliability coefficient for Alpha Cronbach. The following table shows the reliability coefficient of the scale dimensions:

Table (3) : Coefficient of reliability results by using (alphaCronbach) for the social competence scale of social workers

\begin{tabular}{|l|l|l|}
\hline M & \multicolumn{1}{|c|}{ Dimension } & \multicolumn{1}{|c|}{$\begin{array}{c}\text { Alpha Cronbach } \\
\text { Coefficient }\end{array}$} \\
\hline 1 & $\begin{array}{l}\text { Reliability social competence scale of the social } \\
\text { workers as a whole }\end{array}$ & 0.887 \\
\hline
\end{tabular}


The previous table shows that the social competence scale of the social workers has statistically high reliability, which enables us to rely on the findings of the tool.

2. Split-half: The researcher used the Spearman-Brown Prophecy Formula for the semantic fraction, where the phrases of each variable divided into two halves. The first section includes the values obtained from responses to individual paragraphs, and the second section includes the values expressed in the double paragraphs, and the results of the test are as follows:

Table (4) : Coefficient of reliability results by using SpearmanBrown Formula for split-half for the social competence scale of social workers

\begin{tabular}{|l|l|c|}
\hline $\mathbf{M}$ & \multicolumn{1}{|c|}{ Dimension } & $\begin{array}{c}\text { Spearman-Brown } \\
\text { Formula }\end{array}$ \\
\hline $\mathbf{1}$ & $\begin{array}{l}\text { Reliability social competence scale of the social } \\
\text { workers as a whole }\end{array}$ & 0.868 \\
\hline
\end{tabular}

The above table shows that most of the reliability coefficients of variables have a high degree of reliability; thus, their results relied upon, and the tool finalized.

B- The scale of Professional Outcome of Social Work Practice: (Prepared by Mohamed Abdel Hakim Khalaf, 2019)

The scale consists of (30) paragraph to measure the professional outcome of social work practice divided into three dimensions: (Cognitive outcome, skill outcome, ethical and behavioral outcome).

\section{Correction}

To answer the paragraphs of the scale, the researcher used the triangular scale to determine the score for each paragraph, as shown in the following table:

Table (5) : Weights of the paragraphs

\begin{tabular}{|c|c|c|c|}
\hline Response & Achieved & $\begin{array}{c}\text { Achieved to some } \\
\text { extent }\end{array}$ & Not achieved \\
\hline Weight & $\mathbf{3}$ & $\mathbf{2}$ & $\mathbf{1}$ \\
\hline
\end{tabular}

The total score of the scale present in the sum of its partial scores, and for partial measures in the sum of its item scores, whenever the total score higher, this was an indicator of the outcome of professional practice. The maximum score that obtained on the scale, as a whole is (90), and the minimum score (30), as follows:

Table (6)

The distribution of the grades of partial measures and the total degree of the professional outcome of social work practice 
Print ISSN: 2356-9204 Online ISSN: 2356-9212 Vol 9, Issue 1, January 2020

\begin{tabular}{|l|c|c|c|}
\hline $\begin{array}{l}\text { The professional outcome of social work } \\
\text { practice dimensions }\end{array}$ & $\begin{array}{c}\text { Low } \\
\text { grade }\end{array}$ & $\begin{array}{c}\text { Middle } \\
\text { grade }\end{array}$ & $\begin{array}{c}\text { High } \\
\text { grade }\end{array}$ \\
\hline Cognitive outcome & $\mathbf{1 0}$ & $\mathbf{2 0}$ & $\mathbf{3 0}$ \\
\hline Skill outcome & $\mathbf{1 0}$ & $\mathbf{2 0}$ & $\mathbf{3 0}$ \\
\hline Moral and behavioral outcome & $\mathbf{1 0}$ & $\mathbf{2 0}$ & $\mathbf{3 0}$ \\
\hline Total scale & $\mathbf{3 0}$ & $\mathbf{6 0}$ & $\mathbf{9 0}$ \\
\hline
\end{tabular}

Measuring the scale:

The researcher in the current study re-honesty and reliability as follows:

A - Honesty: The researcher relied on two types of honesty:

1. The validity of the arbitrators (the virtual): It includes the ratios of the agreement of the arbitrators on the paragraphs of the scale, where the Scale of Professional Outcome of Social Work Practice was present to several professors of social work, psychology, and field practice to be judged in light of:

1. The extent to which the phrase linked to each axis of the study.

2. In terms of phrase formulation.

3. In terms of content.

Accordingly, the general dimensions of the scale have modified. Some phrases have modified, and the phrases with less than $85 \%$ of the agreement have deleted. The ratio of the agreement has calculated according to the Geithman equation.

2. Internal consistency reliability (factor): The researcher calculated the internal consistency of the scale paragraphs on a sample size of (21) single:

Table (7) : The internal consistency between the variables of the Scale of Professional Outcome of Social Work Practice and the total degree

\begin{tabular}{|l|l|c|c|}
\hline $\mathbf{M}$ & Scale dimensions & $\begin{array}{l}\text { Correlation coefficient with a } \\
\text { total score }\end{array}$ & $\begin{array}{l}\text { Level of } \\
\text { significance }\end{array}$ \\
\hline 1 & Cognitive outcome & 0.888 & 0.000 \\
\hline 2 & Skill outcome & 0.867 & 0.000 \\
\hline 3 & $\begin{array}{l}\text { Moral and behavioral } \\
\text { outcome }\end{array}$ & 0.911 & 0.000 \\
\hline
\end{tabular}

Illustrated by the table above, the dimensions of quality of scale of the professional outcome of social work practice have a statistical significance at a level of (0.05). This indicates the high coefficients of internal consistency as well as referring to the high sincerity and enough of indicators to be trusted in the application of the current study.

B- Reliability: The researcher used two methods to ensure the reliability of the scale: 
1. Alpha Cronbach: The researcher applied the scale to a sample and determined the psychometric characteristics, and then reapplied on the same sample after (15) days, i.e., two weeks between the first application and the second. The researcher then calculated the reliability of the scale of the professional outcome of social work practice by using the reliability coefficient for alpha Cronbach. The following table shows the reliability coefficient of the scale dimensions:

Table (8) : Coefficient of reliability results by using (alphaCronbach) for the scale of the professional outcome of social work practice

\begin{tabular}{|l|l|c|}
\hline M & \multicolumn{1}{|c|}{ Dimension } & \multicolumn{1}{|c|}{$\begin{array}{c}\text { Alpha Cronbach } \\
\text { Coefficient }\end{array}$} \\
\hline 1 & $\begin{array}{l}\text { Reliability scale of the professional outcome of social } \\
\text { work practice as a whole }\end{array}$ & 0.921 \\
\hline
\end{tabular}

The previous table shows the scale of the professional outcome of social work practice. It has statistically high reliability, which enables us to rely on the findings of the tool.

2. Split-half: The researcher used the Spearman-Brown Prophecy Formula for the semantic fraction, where the phrases of each variable divided into two halves. The first section includes the values obtained from responses to individual paragraphs. The second section includes the values expressed in the double paragraphs, and the results of the test are as follows:

Table (9): Coefficient of reliability results by using SpearmanBrown Formula for split-half for the scale of the professional outcome of social work practice

\begin{tabular}{|l|l|c|}
\hline $\mathbf{M}$ & \multicolumn{1}{|c|}{ Dimension } & $\begin{array}{c}\text { Spearman-Brown } \\
\text { Formula }\end{array}$ \\
\hline $\mathbf{1}$ & $\begin{array}{l}\text { Reliability of the scale of the professional outcome of } \\
\text { social work practice as a whole }\end{array}$ & 0.967 \\
\hline
\end{tabular}

The above table shows that most of the reliability coefficients of variables have a high degree of reliability. Thus their results can be relied upon, and the tool became finalized.

Statistical relationship: After the process of data collection and review, the researcher encodes data and discharged by using the Statistical Analysis Program (SPSS V 25.0) and applied the following few statistics:

1. Duplicates and percentages

2. Arithmetic level: 
Table (10) : Levels of arithmetic mean of the five-point scale

\begin{tabular}{|c|c|}
\hline $\begin{array}{l}\text { If the average value of the phrase or dimension ranged between } 1 \\
-2.33\end{array}$ & low level \\
\hline $\begin{array}{l}\text { If the average value of the phrase or dimension has varied } \\
\text { between more than } 2.34-3.66\end{array}$ & Middle level \\
\hline $\begin{array}{l}\text { If the average value of the phrase or dimension has varied } \\
\text { between more than } 3.66-5\end{array}$ & High \\
\hline
\end{tabular}

Table (11) : Levels of arithmetic mean of the Triple -point scale

If the average value of the phrase or dimension ranged low level between $1-1.66$

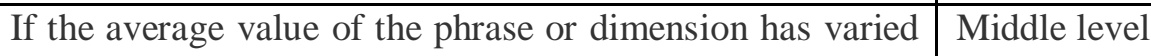
between more than $2.33-1.67$

If the average value of the phrase or dimension has varied High level

between more than $2.34-3$

1. Standard deviation.

2. Cronbach's Alpha

3. Pearson Correlation Coefficient

4. Spearman-Brown Coefficient

5. Chi-Square

6. Gamma

\section{Results:}

First: Statistical description of the sample of the study according to personal data:

\section{Table (12) : Demographic characteristics of the participants}

\begin{tabular}{|c|l|l|l|}
\hline \multicolumn{5}{|c|}{$(\mathrm{n}=146)$} \\
\hline Sr. & Gender & X & $\%$ \\
\hline 1 & Male & $\mathbf{6 8}$ & $\mathbf{4 6 . 6}$ \\
\hline 2 & Female & $\mathbf{7 8}$ & $\mathbf{5 3 . 4}$ \\
\hline Sr. & Social Status & $\mathbf{X}$ & $\%$ \\
\hline 1 & Married & $\mathbf{1 0 7}$ & $\mathbf{7 3 . 3}$ \\
\hline 2 & Single & $\mathbf{1 6}$ & $\mathbf{1 1 . 0}$ \\
\hline 3 & Widowed & $\mathbf{1 6}$ & $\mathbf{1 1 . 0}$ \\
\hline 4 & Detached & $\mathbf{7}$ & $\mathbf{4 . 8}$ \\
\hline Sr. & Age & $\mathbf{X}$ & $\%$ \\
\hline 1 & $20-29$ & $\mathbf{7 8}$ & $\mathbf{5 3 . 4}$ \\
\hline 2 & $30-39$ & $\mathbf{3 1}$ & $\mathbf{2 1 . 2}$ \\
\hline 3 & $40-49$ & $\mathbf{3 2}$ & $\mathbf{2 1 . 9}$ \\
\hline 4 & $50+$ & $\mathbf{5}$ & $\mathbf{3 . 4}$ \\
\hline & Mean & $\mathbf{3 2 . 1 3}$ & \\
\hline & SD & $\mathbf{7 . 8 5 7}$ & \\
\hline Sr. & Qualification & $\mathbf{X}$ & $\%$ \\
\hline 1 & Diploma & $\mathbf{2 5}$ & $\mathbf{1 7 . 1}$ \\
\hline 2 & Bachelor in social work & $\mathbf{1 1 2}$ & $\mathbf{7 6 . 7}$ \\
\hline
\end{tabular}


Egyptian Journal of Social Work (EJSW)

http://ejsw.journals.ekb.eg

Print ISSN: 2356-9204 Online ISSN: 2356-9212 Vol 9, Issue 1, January 2020

\begin{tabular}{|c|l|l|l|}
\hline 3 & Masters & $\mathbf{6}$ & $\mathbf{4 . 1}$ \\
\hline 4 & Ph.D. & $\mathbf{3}$ & $\mathbf{2 . 1}$ \\
\hline Sr. & Years of experience & $\mathbf{X}$ & $\mathbf{\%}$ \\
\hline 1 & -4 & $\mathbf{2 8}$ & $\mathbf{1 9 . 2}$ \\
\hline 2 & $4-7$ & $\mathbf{8 2}$ & $\mathbf{5 6 . 2}$ \\
\hline 3 & $8-11$ & $\mathbf{1 7}$ & $\mathbf{1 1 . 6}$ \\
\hline 4 & $12+$ & $\mathbf{1 9}$ & $\mathbf{1 3 . 0}$ \\
\hline & Mean & $\mathbf{6 . 4 3}$ & \\
\hline & SD & $\mathbf{4 . 0 7 7}$ & \\
\hline
\end{tabular}

The demographic data of the study sample of social workers showed that (ND 146), among them (53.4\%), females were compared to males (46.6\%). Concerning the marital status of the study sample, the results indicated that the percentage of married persons reached (73.3\%). The average age of the sample as a whole was 32.13 years, and the sample concentration in the age group (SD 7.857; Range D 20-29). The majority of the sample of the study confirmed that they hold a bachelor's degree in social work by $76.7 \%$. Their average work experience was 6.43 years and focused their proportion in the (SD 4.077; Range D 4-7).

\section{Table (13) : The level of social competence among social workers}

\begin{tabular}{|l|c|c|c|l|}
\hline Dimensions & Mean & Standard Deviation & Ranking & Level \\
\hline $\begin{array}{l}\text { Confidence and self- } \\
\text { assertion }\end{array}$ & 3.47 & $\mathbf{1 . 0 6 5}$ & 4 & Medium \\
\hline $\begin{array}{l}\text { Communication and social } \\
\text { compatibility }\end{array}$ & 3.54 & $\mathbf{0 . 9 3 9}$ & 1 & Medium \\
\hline $\begin{array}{l}\text { Dealing with societal } \\
\text { problems }\end{array}$ & 3.50 & $\mathbf{0 . 8 5 0}$ & 3 & Medium \\
\hline $\begin{array}{l}\text { Discipline and social } \\
\text { flexibility }\end{array}$ & 3.52 & $\mathbf{0 . 9 6 8}$ & 2 & Medium \\
\hline Total & $\mathbf{3 . 5 1}$ & $\mathbf{0 . 9 0 1}$ & - & Medium \\
\hline
\end{tabular}

It is clear from the previous table that the level of social competence of social workers in the care of special groups is medium; the arithmetic means equal to 3.51. Indicators are in the order of arithmetic mean as follows: It came first after communication and social compatibility with an arithmetic average (3.54). In the second place, after discipline and social flexibility with an arithmetic mean (3.52). Third place after dealing with social problems with an arithmetic mean (3.50). Finally, in fourth place after confidence and self-assertion with an arithmetic average (3.47). 
Table (14) : The level of professional outcome for social work practice among social workers $(\mathrm{N}=146)$

\begin{tabular}{|l|l|l|l|l|}
\hline Dimensions & Mean & $\begin{array}{l}\text { Standard } \\
\text { Deviation }\end{array}$ & Ranking & Level \\
\hline Cognitive outcome & $\mathbf{2 . 2 7}$ & $\mathbf{0 . 3 7 9}$ & $\mathbf{3}$ & Medium \\
\hline Skill outcome & $\mathbf{2 . 3 1}$ & $\mathbf{0 . 6 0 0}$ & $\mathbf{1}$ & Medium \\
\hline Moral and behavioral outcome & $\mathbf{2 . 3 0}$ & $\mathbf{0 . 5 3 7}$ & $\mathbf{2}$ & Medium \\
\hline Total & $\mathbf{2 . 2 8}$ & $\mathbf{0 . 4 3 5}$ & - & Medium \\
\hline
\end{tabular}
professional outcome for social work practice among social workers in the care of special groups is medium; the arithmetic mean equal to (2.28). Indicators are in the order of the arithmetic mean as follows: It came first after skill outcome with an arithmetic average (2.31). In the second place, after moral and behavioral outcomes with arithmetic means (2.3). Finally, in third place after cognitive outcome with an arithmetic average (2.27).

\section{Testing the study hypotheses:}

First Hypothesis: There is a statistically significant correlation with a positive relationship between the social competence of social workers and the outcome of professional practice in the care of special groups.

Table (15) :The relationship between the social competence of social workers and the professional outcome of the practice of social work in the care of special groups

\begin{tabular}{|l|l|l|l|l|c|}
\hline Variable & $\begin{array}{l}\text { Confidence } \\
\text { and } \\
\text { self- } \\
\text { assertion }\end{array}$ & $\begin{array}{l}\text { Communication } \\
\text { and social } \\
\text { compatibility }\end{array}$ & $\begin{array}{l}\text { Dealing with } \\
\text { societal } \\
\text { problems }\end{array}$ & $\begin{array}{l}\text { Discipline } \\
\text { and social } \\
\text { flexibility }\end{array}$ & $\begin{array}{l}\text { The total } \\
\text { score } \\
\text { of the social } \\
\text { competence } \\
\text { scale }\end{array}$ \\
\hline Cognitive outcome & $0.179^{*}$ & $0.216^{* *}$ & $0.267 * *$ & $0.191^{*}$ & $0.533^{* *}$ \\
\hline Skill outcome & $0.180^{*}$ & $0.347^{* *}$ & $0.388^{* *}$ & $0.351^{* *}$ & $0.583^{* *}$ \\
\hline $\begin{array}{l}\text { Moral and behavioral } \\
\text { outcome }\end{array}$ & $0.201^{* *}$ & $0.431^{* *}$ & $0.312^{* *}$ & $0.302^{* *}$ & $0.567 * *$ \\
\hline $\begin{array}{l}\text { The total professional } \\
\text { outcome of social } \\
\text { work practice }\end{array}$ & $0.223^{* *}$ & $0.445^{* *}$ & $0.391 * *$ & $0.455^{* *}$ & $0.584 * *$ \\
\hline
\end{tabular}

The above table shows a statistically significant positive correlation at the level (0.01) between the total of social competence scale of social workers and the dimensions of the scale of the professional outcome of the social work practice in the care of special groups, which confirms the validity of the hypothesis.

It means that whenever the social competence in the sample of study from social workers increases, the professional outcome of the social work practice in the care of special groups increases. Conversely, whenever the social competence of social workers decreases, their 
professional outcomes of social work practice in the care of their groups decreases. It makes us accept the first hypothesis of the study, which was "The relationship between the social competence of social workers and the professional outcome of the practice of social work in the care of special groups."

Second Hypothesis: There is a relationship statistically significant between some demographic variables (gender, age, marital status, academic qualifications, and years of experience) and the degree of social competence.

Table (16):The relationship between some demographic variables and social competence among social workers

\begin{tabular}{|l|l|c|c|c|}
\hline $\mathbf{M}$ & \multirow{2}{*}{ Demographic variables } & Social competence \\
\cline { 3 - 5 } & & Coefficient used & Value and significance & \\
\hline 1 & Gender & Ka 2 & $\mathbf{5 5 . 9 8 4}$ & Df= 46 \\
\hline 2 & Age & Pearson & $\mathbf{0 . 0 1 8}$ & \\
\hline 3 & Marital status & Gamma & $\mathbf{0 . 2 5 7} * *$ & \\
\hline 4 & Educational Qualification & Gamma & $\mathbf{0 . 3 6 2} * *$ & \\
\hline $\mathbf{5}$ & Years of Experience & Gamma & $\mathbf{0 . 0 6 4}$ & \\
\hline & $*$ Significant at 0.01 & Significant at 0.05
\end{tabular}

It is clear from the previous table that there is a statistically significant relationship between one of the demographic variables (marital status and educational qualification) and the social competence of the social workers in the study sample. Social competence does not vary by the difference between the rest of the other variables. It makes us accept the second hypothesis of the study, which was, "There is a relationship statistically significant between some demographic variables (gender, age, marital status, academic qualifications and years of experience) and the degree of social competence."

Third Hypothesis: There is a statistically significant relationship between some demographic variables (gender, age, marital status, academic qualifications, and years of experience) and the outcome of professional practice.

Table (17):The relationship between some demographic variables and the professional outcome of social work practice among social workers

\begin{tabular}{|c|c|c|c|c|}
\hline \multirow{2}{*}{ M } & \multirow{2}{*}{ Demographic variables } & \multicolumn{3}{|c|}{ Social competence } \\
\cline { 3 - 5 } & & Coefficient used & Value and significance & \\
\hline 1 & Gender & Ka 2 & 35.393 & $\mathrm{Df}=46$ \\
\hline 2 & Age & Pearson & $0.226^{* *}$ & \\
\hline 3 & Marital status & Gamma & 0.097 & \\
\hline 4 & Educational Qualification & Gamma & $0.197 *$ & \\
\hline 5 & Years of Experience & Gamma & 0.031 & \\
\hline$* *$ Significant at 0.01 & \multicolumn{4}{|c|}{ Significant at 0.05}
\end{tabular}


It is clear from the previous table that there is a statistically significant relationship between one of the demographic variables (marital status and educational qualification) and the professional outcome of social work practice in the study sample. It means that the level of professional outcome for social work practice varies according to some demographic variables of the social workers' "study sample," and the professional outcome of social work practice does not vary by the difference of the rest of the other variables. It makes us accept the third hypothesis of the study, which was, "There is a statistically significant relationship between some demographic variables (gender, age, marital status, academic qualifications and years of experience) and the outcome of professional practice."

\section{Discussion}

The low skills of social competence lead to the failure of social life, repeated stresses and hardships, and the failure of interpersonal relationships (Goleman, 2006). Social competence represents the ability to express oneself, understand oneself and the social environment, and the ability to act flexibly ( $\mathrm{Wu}, 2008)$. Thus, the social competence of the social workers has directly or indirectly affected his professional performance and hence, on the professional outcome of social work practice, particularly in the care of special groups.

This study attempted to identify the relation of social competence with the outcome of professional practice in a sample of social workers working in the field of care for special groups by testing some hypotheses. The results of the study showed that the level of social competence of social workers in the care of special groups is medium with arithmetic mean equal to 3.51. As for the level of professional outcome for social work practice among social workers (sample study), it is medium the arithmetic mean of (2.28).

When examining and reviewing previous literature and studies, it found that the lack of social competence among specialists and practitioners negatively affects the outcome of professional practice. Effective professional performance requires specialists to have high social competencies (Gerli et al., 2015), and the development of human capital requires continuous improvement in social competence (Emmerling et al., 2012). For example, Hind Mohamed Ahmed Sayed's study (2015) aimed to test the impact of the task-focused model in the social workers' acquisition of social skills in dealing with a child with autism. The study found the effectiveness of the taskfocused model in providing social workers with social skills in dealing with a child with autism. 
By reviewing several previous studies such as Saad Zaghloul Saad (2018), Marwa Ahmed Abdel Fattah (2011), Hind Mohamed Ahmed Sayed (2015) Dalia Mohamed Shafi Dahi (2015), Nemat Hussein Mahmoud (2018), and Ahmed Sayed Abdel Hamid Study (2018) we found that the results of these studies are consistent with the results of the current study on the direct relationship between social competence and professional outcome. Whenever the social competence in the sample of study from social workers increases, the professional outcome of the social work practice in the care of special groups increases.

\section{Conclusion}

The study focused on social competence and its role in improving the outcome of professional practice among social workers in the care of special groups. The present study is one of the rare studies linking the variable dimensions of social competence and the outcome of professional practice with social workers. The results of the study showed that the level of social competence among social workers in the field of care for special groups is average. Moreover, the results of the study indicated that the outcome of the professional practice of social workers' study sample is also average. Thus, the results indicate that whenever the social competence in the sample of study from social workers increases, the professional outcome of the social work practice in the care of special groups increases. As well as whenever the social competence of social workers decreased, the professional outcome of the social work practice decreased. The study also found that there was a statistically significant relationship between one of the demographic variables (marital status and educational qualification) and the social competence of the social workers in the study sample. In addition, there is a statistically significant relationship between one of the demographic variables (marital status and educational qualification) and the professional outcome of social work practice in the study sample. It means that the level of professional outcome for social work practice varies according to some demographic variables of the social workers' "study sample." In light of the present study findings, it is recommended to conduct many types of research on the relationship between social competence and the outcome of professional practice in order to confirm the generalization made in this regard. It also recommends the development of programs aimed at improving the social competence of social workers who are working in the care of special groups.

\section{Research obstacles:}

Researchers faced difficulties related to electronic communication with the participants in the research, which led them to communicate face to face and distribute the tool manually. In addition to the apology of several social workers participating in the research without giving a reason. 


\section{References:}

Abdel Dayem, Ahmed Samir (2018), Efficiency of Professional Performance of Social Workers in Al-Azhar Institutes. Master Thesis, Helwan University, Faculty of Social Work, Department of Social Planning.

Abdel Fattah, Marwa Ahmed (2011), Evaluation of the effectiveness of the training program to improve the professional performance of social workers working in the medical field. Master Thesis, Fayoum University, Faculty of Social Work.

Abdel Hamid, Ahmed Sayed (2018), The effectiveness of a training program from the perspective of the general practice of social work for the development of professional skills among social workers working with children of Duane syndrome with autism spectrum disorders. Doctoral thesis, Assiut University, Faculty of Social Work.

Ahmed, Ahmed Khalifa (2004), Evaluating the outcome of professional practice individual social work with street children in social welfare institutions. Master Thesis, Helwan University, Faculty of Social Work.

Al-Qahtani, Najla Saeed Hassan (2013), A program of social competence in reducing aggression behavior among secondary school students in Saudi Arabia. Ph.D. thesis, Cairo University, Institute of Educational Studies, Department of Educational Psychology.

Amdurer, E., Boyatzis, R. E., Saatcioglu, A., Smith, M. L., \& Taylor, S. N. (2014). Long term impact of emotional, social, and cognitive intelligence competencies and GMAT on career and life satisfaction and career success. Frontiers in Psychology, 5, 1447.

Bedair, Ibtisam Yahya (2008), Planning indicators to increase the effectiveness of the professional performance of the social worker in the school field. Master Thesis, Assiut University, Faculty of Social Work.

Boyatzis, R., Boyatzis, R. E., \& Ratti, F. (2009). Emotional, social, and cognitive intelligence competencies were distinguishing effective Italian managers and leaders in a private company and cooperatives. Journal of Management Development. 28(9), 21-838.

Dahi, D. Dalia Mohamed Shafi (2015), Effectiveness of a training program from the perspective of general practice to achieve the quality of the professional practice of social workers working in the youth welfare services. Ph.D. dissertation, Favoum University, Faculty of Social Work.

El Sayed, Ruqaya Abdel Moneim (2018), Evaluating the outcome of professional practice of individual social workers with behavioral cases for secondary education students. Ph.D. Thesis, Alexandria University, Faculty of Arts, Institute of Social Sciences.

Emmerling, R., Boyatzis, R. E., \& Emmerling, R. J. (2012). Emotional and social intelligence competencies: cross cultural implications. Cross Cultural Management: An International Journal, 19(1), 4-18.

Gerli, F., Bonesso, S., \& Pizzi, C. (2015). Boundaryless career and career success: the impact of emotional and social competencies. Frontiers in psychology, 6 , 1304.

Goleman, D. (2006). Emotional intelligence. Bantam.

Hafeez, Mustafa Gamal Abdel (2017), Requirements to activate the professional performance of social workers with multiple disabilities as indicators for the development of a training program from the perspective of individual social work, Master Thesis, Assiut University, Faculty of Social Work. 
Hamed, Alaa Hamed El-Sayed (2012), The outcome of the local efforts for the rehabilitation of the mentally disabled in the city of Zagazig. Sharkia, Master Thesis, Helwan University, Faculty of Social Work.

Karni, Hind Juma (2016), the requirements of professional practice quality for social workers in working with individual cases in juvenile care institutions. Master Thesis, Fayoum University, Faculty of Social Work.

Mohamed, Samia Arabi (2017), Quality of professional performance of social workers in student activities in accredited and non-accredited colleges. Ph.D. Thesis, Assiut University, Faculty of Social Work.

Muslim, Hassan Ali Hassan (2006). Develop the skills of the social and moral competence of the teacher in order to form a better psychological learner - the 13th Annual Meeting -Saudi Society for Educational and Psychological Sciences, 506 - 534.

Nemat Hussein Mahmoud (2018), A training program for the development of the skills of social workers working with the hard of hearing. Ph.D. Thesis, Assiut University, Faculty of Social Work.

Osman, Samar Tarek Hussein (2019), Professional Practice of Evidence-Based Social Work to Reduce Problems Facing Social Workers who are Working with School Activity Groups. Ph.D. Thesis, Fayoum University, Faculty of Social Work.

Riggio, R. E. (2010). Before emotional intelligence: Research on nonverbal, emotional, and social competences. Industrial and Organizational Psychology, 3(2), 178-182.

Saad, Saad Zaghloul (2018), Effectiveness of the team in providing integrated care for psychiatric patients from the perspective of general practice in social work. Master Thesis, Assiut University, Faculty of Social Work.

Saber, Khaled Awad (2019), Professional Performance Requirements of the General Practitioner in Social Work to Achieve Sensory Integration of Autistic Children. Master Thesis, Assiut University, Faculty of Social Work.

Salah, Hussein Mahmoud (2019), Assessing the roles of the general practitioner in developing life skills for young people. Master Thesis, Assiut University, Faculty of Social Work.

Sayed, Hind Mohamed Ahmed (2015). Using the Task Focus Model in Providing Social Workers with Social Skills in Dealing with an Autistic Child. Ph.D. Thesis, Fayoum University, Faculty of Social Work.

Schneider, R. J., Ackerman, P. L., Kanfer, R. (1996). To "act wisely in human relations:" Exploring the dimensions of social competence. Personality and Individual Differences, 21, pg. 469-481.

Shahid Hosni, Akmal (2015), The Effectiveness of Postgraduate Programs in Improving Professional Performance of Fayoum University Professionals. Master Thesis, Fayoum University, Faculty of Social Work.

Stichter, J. P., O’Connor, K. V., Herzog, M. J., Lierheimer, K., \& McGhee, S. D. (2012). Social competence intervention for elementary students with Asperger's syndrome and high functioning autism. Journal of autism and developmental disorders, 42(3), 354-366.

Wu, Y. (2008). Social skill in the workplace: what is a social skill, and how does it matter? (Doctoral dissertation, University of Missouri--Columbia). 